\title{
DESDICHADA ESPAÑA. DESPOTISMO Y CRISIS POLÍTICA EN EL MEMORIAL HISTORIAL DE FRAY BENITO DE LA SOLEDAD ${ }^{1}$
}

\section{Unfortunate Spain. Despotism and Political Crisis in the Memorial historial by Fray Benito de la Soledad}

\author{
José María IÑURRITEGUI RODRÍGUEZ \\ UNED (Madrid) \\ jinurritegui@geo.uned.es
}

Fecha de recepción: 5/03/2014

Fecha de aceptación definitiva: 22/04/2014

RESUMEN: La historiografía interesada por la cultura política hispana del momento de tránsito entre el Seiscientos y el Setecientos viene asignando un papel marginal al Memorial historial de Fray Benito de la Soledad. Las referencias al texto se circunscriben a la muesca dinástica impresa por su dedicatoria a Leopoldo I y su fijación de la amenaza del despotismo exterior encarnada por Luis XIV. Se omite sin embargo cualquier referencia al programa de reformación de la monarquía que con el lenguaje de la uniformidad, y desde la identificación de un despotismo interior, despliegan unos discursos centrales cuya versión manuscrita ya se había presentado a Carlos II y al propio Luis XIV. Y con ello se pierde no solo el anclaje de la obra en el proceso de introspección política gestado en el seno de la monarquía antes de la guerra de sucesión, sino la posibilidad misma de reconocer que en su contexto se hicieron presentes lenguajes políticos de cuya complejidad difícilmente puede rendirse cuenta con la mera y exclusiva referencia a la implicación dinástica de sus autores.

1. Este trabajo forma parte de las actividades de los proyectos de investigación HAR2011-27562, Repensando la identidad: la Monarquía de España, 1665/1746 y HAR2012-37560-CO2-01, Conservación de la Monarquía y equilibrio europeo en los siglos XVII-XVIII. 
Palabras clave: Despotismo; Crisis política; Cortes; Benito de la Soledad; Carlos II; Felipe V.

ABSTRACT: Historiographers interested in Spanish political culture in the transition between the $17^{\text {th }}$ and $18^{\text {th }}$ centuries have traditionally assigned a marginal role to the Memorial historial by Fray Benito de la Soledad. References to the text focus mainly on its dedication to Leopoldo I and his fixation on the threat of external despotism that Louis XIV represented. However, they omit any reference to the monarchy's program of reform that his main discourse deployed with a language of uniformity, and from a point of view of identification of a domestic despotism, and whose manuscript version had already been presented to Charles II of Spain and Louis XIV. It is often forgotten that his work was anchored to the process of political introspection formulated in the heart of the monarchy before the War of the Spanish Succession, and we have lost sight of the possibility of recognizing that political languages were included in its context whose complexity can hardly account for the mere and exclusive reference to the dynastic involvement of its authors.

Key words: Despotism; Political crisis; Cortes; Benito de la Soledad; Charles II of Spain; Philip V.

A la altura de 1835, y en dos largas notas a pie de página de su Examen bistórico, Agustín de Arguelles exhumaba una obra del franciscano Benito de la Soledad publicada en 1703 en Viena: el Memorial historial y politica cristiana, que descubre las ideas y máximas del Cristianísimo Luis XIV para librar a la España de los infortunios que experimenta por medio de su legítimo Rey Don Carlos III. No era este, en principio, un título que anunciara una entrada natural de su asunto y materia en la recapitulación que trazaba Arguelles del tiempo y experiencia de reforma constitucional iniciado en 1808 y culminado en 1812. Incorporaba no obstante su Examen una reconstrucción de los tortuosos avatares históricos de la nación en cuyas específicas coordenadas se esbozaba una particular vinculación entre los momentos de crisis de principios del Setecientos y del Ochocientos. "El grave yerro cometido en la guerra de sucesión -afirmaba Arguelles-, estaba demasiado vivo en la memoria de toda persona ilustrada y prudente para que se desconociese que la independencia de un Estado no se puede establecer con solidez sin instituciones que aseguren la libertad interior " ${ }^{2}$. Y tampoco dejaba además

2. ARguelLes, Agustín de. Examen histórico de la reforma constitucional que bicieron las Cortes generales y extraordinarias desde que se instalaron en la Real isla de León el día 24 de setiembre de 1810 hasta que cerraron sus sesiones en 14 del propio mes de 1813. Londres: Carlos Wood, 1835, pp. 120, 125 y 135-154 Sobre el texto, y por lo que aquí interesa, véase, PorTillo Valdés, José María. Revolución de nación. Orígenes de la cultura constitucional en España, 1780-1812. Madrid: Centro de Estudios Políticos y Constitucionales, 2000, pp. 208 y ss. 
de precisar que semejante yerro no implicaba que en el horizonte de la intrincada encrucijada sucesoria de 1700 no hubieran comparecido algunas "memorias nacionales" compuestas justamente con la "patriótica" pretensión de prevenirlo y conjurarlo. Aún fallidas en su intento de neutralizar el establecimiento de un modelo de gobierno despótico, llamado a reducir a cenizas el "espíritu de libertad" y las "antiguas instituciones", convenía por tanto tenerse en cuenta y consideración que el aletargado estado de "suma indiferencia y abandono" entonces fraguado al son de "intereses incompatibles con lo que convenía a la nación" había tenido sus excepciones. Y la convocatoria del Memorial historial de Benito de la Soledad, o la paralela referencia a la Enfermedad crónica de España de Juan Amor de Soria, cuyo conocimiento confesaba deber a la Teoría de las Cortes de Francisco Martínez Marina, cumplían como ilustración al respecto.

Tras vincular el largo ostracismo del Memorial historial con un despliegue también "literario" del absolutismo, Arguelles fundamentaba su labor de exhumación apelando no tanto a lo que anunciaba el título de Benito de la Soledad sino a una concreta veta argumental velada en esa titulación: al ambicioso programa de reformas que descubría hilvanado en el texto y que, afectando a la legislación y "a casi todos los ramos de la administración pública", aspiraba a circunscribir las "facultades" de los Consejos "a la mera administración de justicia" ${ }^{3}$. Tampoco escatimaba además ciertas concreciones sobre el preciso sentido y significado de la específica adjetivación nacional con la que, así leído, procedía a catalogarlo. Por ello, y una vez registrada la militancia de su autor en las filas del "partido del Archiduque", promovía como imperativo primario para su ajustada comprensión la necesidad de conjurar el riesgo del deslumbramiento que esa muesca y filiación dinástica podía provocar en la fijación de la intención con la que aquella memoria nacional había sido concebida y compuesta. Y así, sumergiéndose en los matices, venía a sentenciar que "este partido no sostenía a aquel pretendiente solo porque lo consideraba con mejor derecho a la corona, sino también porque lo suponía más dispuesto a remediar los males que afligían a España que un príncipe francés". Afilada ya en su propio enunciado exento, la matización solo adquiría sin embargo su verdadera hondura y envergadura cuando se cruzaba con el profundo escepticismo que Arguelles albergaba respecto a los efectos que sobre las desventuras de la nación se hubieran podido derivar de una hipotética resolución de aquella crisis sucesoria en una clave dinástica alternativa. De hecho, la controvertida idea sobre el grado de probabilidad de que el Archiduque Carlos, "si hubiese salido victorioso, hubiera hecho lo mismo que su competidor", esto es, lo mismo que "un príncipe francés que, apenas subió al trono, cuando adoptó

3. Para la noción de absolutismo literario, y su aplicación al momento de composición del Memorial de Benito de la Soledad, véase Hill, Ruth. Sceptres and Sciences in the Spains. Four Humanists and the New Philosophy (ca. 1680-1740). Liverpool: Liverpool University Press, 2000, pp. 1-27. 
máximas y principios de administración y gobierno que acabaron de aniquilar los derechos y libertades de la nación", no le era ciertamente ajena.

Es indudable que el propio Benito de la Soledad, o Juan Amor de Soria, no hubieran sentido ninguna comodidad y complicidad con aquel razonamiento y aquella forma de razonar que venía así a cuestionar y a relativizar la trascendencia que entrañaba el componente dinástico en la fijación del rumbo trágico que la historia de la nación definitivamente había tomado en el momento inaugural del Setecientos. La propia reunión de ambos autores, que habían en realidad compuesto sus obras en momentos políticos radicalmente distintos, antes de la apertura de la guerra civil Benito de la Soledad, y décadas después de la cancelación de la misma Juan Amor de Soria, no dejaba de constituir una cierta licencia y libertad de lectura. Y es notorio que muchos de sus contemporáneos no hubieran suscrito ni comulgado nunca con esas palabras de Arguelles. Alguno de ellos, como el concreto caso de Antonio de Capmany, ni siquiera entendía que pudiera trazarse un paralelismo entre la guerra a la que convocaba con su Centinela contra franceses y la que a la muerte de Carlos II había motivado su sucesión, a la que se refería más bien como un mero "pleito de familia" librado además "entre dos nobilísimos príncipes, muy dignos cada uno de ocupar el trono de las Españas" ${ }^{4}$.

En la esfera más concreta y apegada a la lectura del Memorial, la de su propia letra, contexto e intención, Agustín de Arguelles no era pese a todo la única figura de aquel primer constitucionalismo que se sentía atraída por el texto de Benito de la Soledad y se mostraba dispuesta a reconocerle una marcada y sugerente personalidad política. Al margen de su llamativa invocación en el seno de los debates y deliberaciones de las Cortes constituyentes de 1837, desde las páginas de la Historia del levantamiento, guerra y revolución de España, cuyos primeros libros se imprimían el mismo año de la publicación del Ensayo histórico, el Conde de Toreno también confesaba su aprecio por el Memorial y las razones que lo motivaban. Y las mismas resultaban ser idénticas a las ofrecidas por Arguelles al exhumarlo: "admira que a principios del siglo XVIII se tuviesen ideas tan claras sobre varios de los males administrativos que agobiaban a España y sobre la necesidad de separar la parte gubernativa de la judicial, ${ }^{5}$.

Otra cosa bien distinta es que la clave de lectura así trazada, y el lenguaje con el que se trazaba, terminaran modificando la suerte historiográfica del Memorial bistorial. Su renacimiento en el seno de esa reflexión política que contextualizaba la crisis de 1808 en las coordenadas de la evolución histórica de la monarquía no tuvo continuidad en la historiografía atraída por el estudio de la gestación y sus-

4. CAPMAnY, Antonio de. Centinela contra franceses. Madrid: Gómez Fuentenebro y Compañía, 1808, pp. 24-26.

5. COnde De Toreno. Historia del levantamiento, guerra y revolución de España. Madrid: Imprenta de Tomás Jordán, 1835-1837, II/IX, pp. 104 y ss. y 123 y ss. y Cortes constituyentes de la nación española. Diario oficial de las sesiones de enero y febrero de 1837. Madrid: Imprenta del Eco del Comercio, 1837, I-II, p. 164. 
tanciación de la crisis de 1700. La posición marginal y el habitual papel testimonial que la obra ocupa y desempeña en las recientes tentativas de identificación de la enrarecida atmósfera que envolvió ese momento de cambio político bastan para clarificar y certificar el movimiento pendular que la misma historiográficamente ha conocido. Es más, el autor lúcido y adelantado a su tiempo histórico que vislumbraban tanto Arguelles como el Conde de Toreno ha podido transformarse entretanto en un simple compositor de "memoriales fantásticos e irrealizables", e incluso en un compulsivo redactor de arbitrios desarticulados ${ }^{6}$. Así despachado, no hay ya el más mínimo rastro del reconocimiento de la voz propia con la que una cultura política hispana se habría personado en tan incierto momento de cambio y a la que, a su modo y manera, y con su particular vocabulario de nación, aludían las tempranas recapitulaciones de la experiencia constitucional y constituyente gaditana. Pero quizás las mismas no estaban tan llanamente desencaminadas al leerlo en esos términos.

De entrada, el Memorial historial no era el único texto de Benito de la Soledad que en el agitado otoño de 1703 publicaba en Viena el impresor italiano Juan Van Gehlem. Bajo su sello editorial, y suscrito por el franciscano, aparecía también un par de meses después que el Memorial un Manifiesto que explica el derecho de la Magestad Cesarea del Señor Emperador a la Monarchia de España y evacuativo de la indebida pretensión del Duque de Anjou, que violentamente la ocupa contra el derecho de las gentes, natural, positivo, canónico y civil. Encerraba ese Manifiesto su novedad. Venía por supuesto a sumarse al rosario de textos que por aquello años colocaban el saber jurisprudencial al servicio de la retórica de las diferentes instancias dinásticas entonces comprometidas en la determinación del orden sucesorio de la monarquía hispana. Pero resultaba ser el primer tratado compuesto en lengua castellana que asumía monográficamente por motivo y materia ese intenso debate jurídico de la localización dinástica de la soberanía. Su redacción era algo que se anunciaba ya en las páginas del Memorial historial ${ }^{\text {. }}$. Y al publicarlo Benito de la Soledad liquidaba ese compromiso previamente adquirido con los lectores de aquel texto que, aún presto siempre a decretar que "la Francia no puede alegar derecho a la corona de España", tampoco dudaba al consignar desde la dedicatoria al emperador Leopoldo I que no era la querella de los derechos dinásticos el terreno que básicamente aspiraba y procuraba

6. Cfr. Domínguez OrTiz, Antonio. La sociedad española en el siglo XVII. Madrid: CSIC, 1963, II, pp. 203/204 y Del Río PARRA, Elena. Cartografías de la conciencia española en la Edad de Oro. México: Fondo de Cultura Económica, 2008, p. 116.

7. Archives Nationales de France, AD-XV-33.

8. SOlEDAD, Fray Benito de la, Memorial bistorial y politica cristiana, que descubre las ideas y máximas del Cristianísimo Luis XIV para librar a la España de los infortunios que experimenta por medio de su legítimo Rey Don Carlos III. Viena: Juan Van Gehlem, 1703, pp. 3 y 430, donde se precisaba su determinación de "dar más cabal cuenta" al respecto en "el Manifiesto que haré sobre el derecho a la Monarquía de España". 
desbrozar con su escritura9. Filtrando una significativa jerarquización de prioridades, el Memorial que precedía al Manifiesto entregaba con determinación sus letras a la fijación de una lectura del momento político hispano bajo la cifra primaria de una crisis dinástica pero también constitucional, novedad aún mayor que la que le revestía por cuestión de idioma.

Flanqueado por la comparecencia del Manifeste de Leibniz, o por la más sistemática Alegación jurídica de inmediato compuesta por el portugués Alejandro de Herrera, aquel Manifiesto de Benito de la Soledad pronto se configuró como uno de los pilares a los que el entorno del Archiduque encomendó el anclaje sobre el zócalo del derecho de su "llamamiento a la nación española "10. Exponente del uso dinástico entonces dado a ese género de escritos de impronta jurídica, la propia incorporación del Manifiesto o de la Alegación de Herrera al debate de la fidelidad política de inmediato abierto en la escena catalana no dejó de ser una operación textual expresamente promovida desde Viena. Menor complicidad dinástica y compañía textual encontró sin embargo el Memorial historial, que a partir de yacimientos discursivos ya explotados con asiduidad hilvanaba una sostenida denuncia y crítica de la utilización patrimonial de la soberanía ciertamente singular en las coordenadas argumentales dominantes de la literatura jurídica y política de su tiempo.

Internamente dispuesto y dividido en dos tratados cuyo acentuado perfil otorgaba una apariencia bifronte al conjunto del texto, nada innovaba el primero de los mismos, ni cuando contextualizaba los recientes y tortuosos avatares políticos hispanos en el horizonte de la aspiración de Luis XIV al "señorío del Orbe", ni cuando identificaba la esencia de la nueva forma de "gobierno tiránico" implantada en la monarquía tras el cambio dinástico de 1700 en la modalidad de despotismo que entendía enraizada y acunada en las "perversas doctrinas de Mazzarino" ${ }^{11}$. Y tampoco incorporaba ningún planteamiento que pueda decirse rupturista al disponer el segundo de sus tratados como una minuciosa exploración encaminada a diagnosticar los males que afectaban a la monarquía y a prescribir los remedios que podían y habían de conducirla a su restauración $n^{12}$. De todo ello

9. SOlEDAD. Memorial historial, p. 100.

10. IÑURRITEgui, José María. "Jus in armis. Texto y contexto de la Alegación jurídica de Alejandro de Herrera". En MarTín Marcos, David (ed.). Monarquías encontradas. Estudios sobre Portugal y España en los siglos XVII y XVIII. Madrid: Sílex, 2013, pp. 139-175.

11. Soledad. Memorial historial, pp. 13 y ss.; Salvador, Miguel. Verdad política. Amsterdam: Henri Desbordes, 1694; EnRíQuez de CABrera, Juan Tomás. Manifiesto del Almirante de Castilla Juan Tomás Enriquez de Cabrera y correspondencia con el emperador Leopoldo I. Biblioteca Nacional (en adelante BN), Micro 20048 (ff. 70-104), y La salud de la Europa considerada en un estado de crisis. Zaragoza, 1694.

12. Véase al respecto tanto la ilustrativa "anatomía del cuerpo político de esta Monarchía" trazada en la Consulta del Consejo de Castilla del 6 de diciembre de 1694 (BN. mss. 10919, fols. 59-92) como el diagnóstico coincidente de los males, pero radicalmente distinto de sus remedios, que se identificaban con la adopción del modelo político francés, cerrado en la Representación hecha a la 
se venía escribiendo con frecuencia e intensidad ${ }^{13}$. Pero lo que ya no resultaba tan usual era la fusión de ambos registros en un mismo texto. Y mucho menos aún que se fusionaran con la confesada intención de acreditar que el único cauce para alcanzar la "justa composición" de la monarquía pasaba por atajar no solo el sobrevenido despotismo francés, sino también, y con la misma determinación, el despotismo togado que Benito de la Soledad decía irradiarse y afirmaba imponerse sostenidamente en las últimas décadas desde el Consejo y la Cámara de Castilla ${ }^{14}$.

La muy particular historia del texto guardaba en realidad una estrecha relación con la posición así tan excéntrica y personal que adoptaba frente a las rígidas convenciones discursivas entonces más propiamente dinásticas. Según se dejaba puntual constancia ya en su presentación, la obra albergaba algunos fragmentos redactados en los últimos meses y otros compuestos desde comienzos de la última década del siglo anterior. De hecho se hacía saber al lector que el tratado segundo, el dedicado al desvelamiento del despotismo interior, no era sino una versión trenzada de los diferentes memoriales que a partir de 1691 había puesto a disposición de Carlos $\mathrm{II}^{15}$. Y tampoco dejaba de precisarse en sus páginas que la pésima recepción que entonces les habían dispensado los miembros de la Junta Magna constituía una ilustración diáfana de la cautividad de la soberanía cuya liberación ya se antojaba así indispensable antes de la traumática irrupción en escena del expediente de utilización patrimonial y exterior de la misma encarnado en la figura de un Felipe V, a quien por lo demás, y en ese concreto sentido, se catalogaba como una mera sombra de Luis XIV. La entrada limpia que el Memorial daba a aquellos memoriales, sin siquiera sentir la necesidad de modificar su redacción original, no se limitaba por tanto a certificar una inquebrantable fe en la validez de sus iniciales propuestas de reformación de la monarquía. Constituía también, y de forma nada velada, un ferviente llamamiento a evitar que la nueva dimensión y deriva en la que esa crisis se había luego adentrado al compás de la encrucijada sucesoria velará el necesario reconocimiento de la amenaza que, para la restauración del orden propio e histórico de la monarquía, entrañaba la dinámica de erosión de la función política de unas instituciones tradicionales,

Magestad del rey Don Carlos Segundo por el Obispo de Solsona, en el año 1694, en que descubre los males de este Reyno, que consulto por su edición en Semanario Erudito. Madrid: Antonio Espinosa, 1790, v. XXIX, pp. 256-278.

13. Fernández Albaladejo, Pablo. La crisis de la monarquía. Barcelona: Crítica-Marcial Pons, 2009, caps. 6 y 7; BosBach, Franz. Monarchia universalis. Göttingen: Vandenhoeck \& Ruprecht, cap. 5 y SChILlinger, Jean. Les pamphlétaires allemands et la France de Louis XIV. Berna: P. Lang, 1999.

14. SOlEdAD. Memorial historial, "Prologo al lector" y pp. 4-8.

15. Los mismos pueden consultarse en la Biblioteca Nacional (V. E., 17-9, 17-16 y 191-114), en la Real Academia de la Historia (R-42, 215/242; 9/3601 (1); 11/9389 (522-1): 11/9399 (522-2); 14/11438 (19) y Caja 931, n. ${ }^{\circ}$ 20789) y en el Monasterio de las Descalzas de Madrid, MD/H/147 (1161430) y $\mathrm{MD} / \mathrm{H} / 148$ (116143). 
comenzando por las Cortes, en la que se vislumbraba el inconfundible sello del interés de los togados.

Como igualmente se puntualizaba, en el tránsito y trasvase desde su versión original manuscrita hasta su impresión en el cuerpo del Memorial, aquellos memoriales habían recorrido además un inusual itinerario cuya reconstrucción no dejaba de esclarecer y situar en sus justos términos el sentido y el significado de la adscripción dinástica final con la que la obra comparecía en $1703^{16}$. Rememoraba al respecto Benito de la Soledad que el enfrentamiento con la Junta Magna presidida por el marqués de Mancera y comisionada para escrutar la viabilidad y pertinencia de sus memoriales, a partir de cuyo dictamen el superintendente de impresiones Isidro Camargo procedía a denegar la licencia para su publicación, lo había obligado a refugiarse en Roma, desde donde había contemplado e interiorizado la secuencia del cambio en la cabecera monárquica de 1700 como una ocasión para dar a sus propuestas el vuelo que antes le había sido negado, lo que entrañaba una doble confesión: por un lado, la de reconocer que a esas alturas no albergaba ninguna otra preocupación más apremiante que la de promover su particular cruzada contra el despotismo del Consejo de Castilla, razón por la que, lejos de caer en el desánimo, había sometido sus repudiados memoriales a la lectura y consideración de figuras como la del marqués de Villena o el prepósito general de la Compañía de Jesús, Tirso Gonzalez de Santallana; y por otro, relacionada con esta, la de evidenciar que durante su estancia romana tampoco otorgaba mayor crédito a un concreto texto, la Risposta al Discorso fatto a Sua Santita dal Segnor Rabenac, que entonces leía y al que luego el Memorial convertía en la pieza maestra para quien quisiera descubrir las claves que infundían la pretensión universalista de Luis $\mathrm{XIV}^{17}$. Por eso mismo, continuaba relatándose, no había dudado en trasladarse hasta París pertrechado con sus memoriales para someterlos a la consideración de la corte de Versalles. Pero justo en ese momento, según advertía el franciscano a los lectores del Memorial, justo en aquellos intensos días de 1701 en los que incluso llegó a reunirse con el poderoso marqués de Torcy, toda esa maniobra de aproximación se había trasformado en su particular camino de Damasco, narrándose oportunamente el episodio como una experiencia de descubrimiento y adquisición de conciencia del abismo de la tiranía y la esclavitud por el que se había sumido el reino de Francia bajo el gobierno de Luis XIV, y de la manera en que la "sujeción de España" por él fraguada "contra todo derecho divino y humano" liquidaba el único obstáculo que en verdad lo separaba de su aspiración a la "monarquía universal" ${ }^{18}$.

16. SOlEDAD. Memorial historial, pp. 68, 74-86, 97, 113-114, 292-294 y 433-434.

17. Risposta al Discorso fatto a Sua Santita dal Segnor Rabenac, inviato del Re Cristianisimo. Colonia: Cristiano Bonnefoy, 1693. Para la remisión al mismo por parte de Benito de la Soledad, véase Memorial historial, pp. iii/iv.

18. SOlEDAD. Memorial historial, pp. 13-35. 
No era sin duda este un género de confesión que pareciera fortalecer la autoridad del Manifiesto que dos años después componía Benito de la Soledad y que venía a negar la validez jurídica de aquellos términos de resolución de la encrucijada sucesoria hispana que precisamente en 1700 había asumido con absoluta naturalidad. Fijaba no obstante con suma exactitud el preciso momento en el que había virado en términos dinásticos y había así comenzado a hilar y madurar el contundente discurso sobre el despotismo francés que también en 1703 formalizaba en el primero de los tratados de aquel Memorial cuyo título llegaba casi a monopolizar aún cuando no hiciera plena justicia a su más amplio contenido. Y filtraba a su vez que lo que nunca había variado en su retórica durante todo ese tiempo era aquel otro ramal argumental empeñado en activar un proceso de introspección política que posibilitara "descubrir los daños de la Monarchia Española" y que permitiera igualmente identificar "los medios para lograr su justa composición" "19. No había ni podía haber por tanto doblez en su dedicatoria al emperador Leopoldo I, a quien al fin y al cabo no se ocultaba que era en realidad el tercer soberano cuyo amparo y complicidad se buscaba para aquellos memoriales que antes habían sido ya personalmente presentados a Carlos II en Madrid y a Luis XIV en París.

Sin mengua de la posibilidad de encumbrar al Archiduque a la categoría de "libertador de España", y de figurarlo como el "nuevo salomón" llamado a "restaurar el punto de la Monarchía", resultaba por tanto lógico y acorde con esa trayectoria que los "políticos españoles" ya no comparecieran en el Memorial como los destinatarios del texto ${ }^{20}$. En ese sentido, y con el vuelo adquirido desde que algo más de un siglo atrás lo acuñara el jesuita Pedro de Ribadenira, el propio esquema de comprensión del tiempo presente como un nuevo episodio de tribulación sobre el que se alzaba el Memorial portaba el fruto de una labor introspectiva consagrada tanto a la identificación de los "pecados públicos" a los que obedecía la "pérdida del favor divino" como a la definición de las vías de enmienda de los mismos, y así de superación de unos males cuya plasmación más dramática se descubría en la sostenida deriva política consumada por la "pérdida del don de govierno". Apegado a la lectura de la política en clave medicinal que tanto arraigo había tenido en la tradición cultural hispana desde mediados del Quinientos, la propia caracterización como "médicos" que el Memorial historial dispensaba al Emperador y al Archiduque no implicaba por tanto, ni mucho menos, que la naturaleza del "mal" que requería la "curación de la monarchía" hubiera de ser por ellos detectada, o que el "remedio que se tiene por único para componer la Corona de España" precisara de alguna definición por su parte ${ }^{21}$. Lo que a uno y a otro por el

19. SOLEDAD. Memorial historial, pp. 4-8.

20. SOLEDAD. Memorial historial, pp. 68-70, 83 y 154 .

21. Soledad. Memorial historial, pp. 81, 174, 246 y 405. Para la fragua del discurso de la tribulación y su anclaje sobre una comprensión providencial del tiempo secular, véase, IÑURRITEGUI, José 
contrario les incumbía en la exhortación de Benito de la Soledad era invertir esa pérdida del "don de gobierno", y la del favor divino a la que obedecía, a través de una decidida acción normativa cuya concreta orientación venía ya dada por el diagnóstico y la prescripción del tratamiento que, tras huir de Francia, embarcarse en Portugal, pasar por Malta, Messina y Venecia, y llegar hasta Viena, el franciscano ponía a su disposición en nombre de esos políticos españoles.

Lejos de los textos que como la Alegación jurídica de Alejandro de Herrera instruían a la nación española en la prudencia del derecho, y también lejos de los que al modo del Manifiesto del Almirante de Castilla circunscribían su censura del despotismo a la realidad dinástica presente, la consideración crítica del tortuoso devenir político de la monarquía anterior a la concreción de la crisis de 1700 encontraba así, y por la propia naturaleza de aquel ejercicio de introspección, un cauce de entrada y acomodación en el debate del tiempo. No se trataba, por supuesto, de relativizar la responsabilidad de Luis XIV en la "ruina de nuestra Monarchía". Todo el primer tratado del Memorial se componía precisamente para desvelar que el norte de actuación del Cristianísimo se cifraba en la "perversa pretensión" de convertirse en "dueño despótico y señor absoluto de la Monarchía", y para reseñar a su vez que la "supresión de los derechos territoriales", el "desvanecimiento de los Consejos" y la "usurpación de las haciendas de los vasallos" conformaban el trípode sobre el que tal designio patrimonial había de sustentarse. Pero una vez asentado y bien asentado todo ello, lo que en verdad interesaba a Benito de la Soledad era recomponer la dinámica política interna por la que aquel expediente despótico había podido llegar a concretarse. Y era en ese terreno donde irrumpía un sujeto corporativo al que sin medias tintas se imputaba una responsabilidad política suprema en las desventuras propias: "todos los daños de la Monarchía Española han nacido de los togados" ${ }^{22}$.

Movida por el "interés propio" y sin consideración alguna hacia el "bien de la Patria", concebida para "adueñarse de la bolsa del Rey", la identificación de una "política de los togados", cuyo despliegue habría condicionado radicalmente el Seiscientos político hispano, proporcionaba a Benito de la Soledad una poderosa y abundante munición. Dotaba primeramente a su reflexión de una clave a partir de la cual podían explicarse pliegues políticos tan variados como la "ruina de la Hacienda Real", el ostracismo y marginación de las Cortes, la desnaturalización de la original función consultiva de los Consejos, la "perturbación de las leyes del Reyno de Castilla", e incluso la pujanza de unas doctrinas regalistas, cuya cumbre suprema situaba en las obras de Francisco Salgado de Somoza y José de Ledesma, a las que se llegaba a atribuir la erosión de "la obediencia del monarca hispano

María. "Providencia, gracia y virtud: Discurso católico en tiempos de tribulación". En De BeRNARDO ARES, José Manuel (ed.). El hispanismo angloamericano. Córdoba: Universidad de Córdoba/Cajasur, 2001, pp. 979/995.

22. SOledAD. Memorial historial, pp. i-ii, 16, 45-46, 147 y ss., y 249. 
a la cabeza de la Yglesia" ${ }^{23}$. Retratados como "los Aquiles de todo desorden", e imputados como "traidores de su Rey y su Patria", colocar en el centro de aquella operación crítica a los togados le posibilitaba además conducir otro de sus empeños mayores: demostrar lo "mal fundada" que estaba la "máxima común" por la que se consideraba en Europa "que los Grandes son la causa de la destrucción de España ${ }^{24}$. Ningún fruto de esa tarea de cartografiar la política de los togados en sus muy diversos ámbitos de concreción resultaba sin embargo comparable con el de la posibilidad que le abría para cifrar el motivo fundamental por el que el "fatal empeño" del monarca, y el bloqueo de toda tentativa encaminada a su “justo desempeño", habían terminado configurándose como males estructurales de la monarquía y así precipitando la "destrucción de España" ${ }^{25}$. Por eso mismo, una vez abierto y aquilatado ese ángulo interpretativo, nada se enfatizaba tanto en sus páginas como la necesidad de evitar que el nuevo Salomón perdiese de vista que si Luis XIV, instruido en las "máximas machiavellianas" de Mazzarino, había leído la encrucijada dinástica de 1700 bajo la cifra de los momentos de oportunidad política, y en términos así de ocasión, algo tenían que ver en el asunto, y no precisamente poco, aquellos togados que habían provocado que la monarquía llegase a ese crucial escenario desprovista de "sustancia" y "ajustado govierno".

Cierto es que entre 1698 y 1700 la consideración de la crisis dinástica se había vista ya acompasada, ante la irrupción de unos tratados elocuentemente dichos de reparto de la Monarquía de España, por la interiorización de una crisis de soberanía ${ }^{26}$. Es más, en algunos textos dispuestos en ese sentido se contenía incluso un cierto apunte de crisis constitucional, procediéndose a censurar con acritud el protagonismo político asumido por el Consejo de Estado en aquella encrucijada al «intentar que el Rey se haya de conformar a su influjo, abrogándose las prerrogativas del parlamento de Ynglaterra o del Senado de Venecia con su Dux" ${ }^{27}$. Y de todo ello se hacía cargo Benito de la Soledad al censurar "la división inicua que viviendo la Magestad de mi Rey y Señor D. Carlos II quiso hacer de la Monarchía Española el Rey Luis XIV", y al cargar las tintas sobre los "traidores a la nación" que, equiparados a la figura del Conde Don Julián y encabezados por el cardenal Portocarrero, finalmente habían entregado la Monarquía al "caballo troyano" del

23. SOlEDAD. Memorial historial, pp. 153-157, 168, 174 y 403 y ss. El texto previo del propio autor que en materia de inmunidad eclesiástica se vierte en el Memorial es la Respuesta al papel del Señor D. Joseph de Ledesma, Fiscal del Consejo Real sobre las competencias con el Sr. D. Toribio de Mier por la inmunidad eclesiástica (BN. Mss. 11014).

24. SOlEDAD. Memorial historial, pp. 50, 88, 158-160 y 249.

25. "No quieren dar a nada buena forma, aunque la Monarquía se pierda, el Rey esté sin fuerzas y medios, y los vasallos perdidos y arruinados», Soledad., Memorial historial, pp. 251-52, 261 y 265.

26. VICENT, Ignacio. "Entre prudentes y discretos. La conservación de la Monarquía ante el Tratado de Repartición de 1700". Espacio, Tiempo y Forma, 4, 9, 1996, pp. 323-337.

27. Reflexión sobre el estado presente de las cosas de Europa y esta Corte con el motivo de la repartición de la Monarchia, BN. Mss. 10919, ff. 97 y ss. 
Cristianísimo. Pero lo hacía sin perder nunca de vista su firme convicción de que la crisis dinástica y la crisis de soberanía solo podían entenderse y atajarse desde la lúcida constatación de la concurrencia también de una sostenida crisis constitucional que, iniciada "habrá poco más de ciento cincuenta años", había terminado "formando con el curso del tiempo un cuerpo tan monstruoso" 28 .

Esa cruda imagen de una monarquía "deshecha y desbaratada" bajo el despotismo de los togados no debía impedir sin embargo que se reconociera la existencia de alguna sólida garantía con las que afrontar el proceso de reformación. La convicción de que "no está España tan acabada como comúnmente se cree" bastaba para anunciar que, pronta y debidamente tratada, no habría de esperarse mucho para asistir a la conversión de la monarquía en un "paraíso". Dando sentido a la adjetivación con la que se presentaba el Memorial, la historia ya permitía reconocer que había habido en el pasado unos "tiempos felices" singularizados por la ausencia de cualquier "tiranía de los togados" y marcados por la vitalidad con la que la nobleza y las Cortes mantuvieron "el punto de la Monarchia". Aún de manera indirecta y velada, y así bien distinta a la referencia directa que ese episodio crucial de la historia constitucional castellana recibía en la literatura política catalana entonces comprometida con la defensa de sus libertades territoriales, el capítulo de la comunidades de Castilla comparecía en ese sentido como un verdadero momento de cesura, asumiéndose así como premisa que si las Cortes hubieran tenido una intervención más activa en los últimos reinados «es bien cierto que no hubieran llegado las cosas al estado en que se hallan ${ }^{29}$. El remedio para tan desolador panorama se antojaba por tanto evidente. Requería, por un lado, tener bien presente la certeza de que "mientras que los monarcas que governaren en España no la dispusieren por sí, dando la cabal forma con unas Cortes y sin dejar el govierno a los Consejos, se hallará cada día más trabajosa la España". Y reclamaba por otro obrar lógicamente en consecuencia, esto es, que el monarca procediera de inmediato a "buscar la asistencia del Reyno en Cortes" para dar "nueva forma a la Monarchía" ${ }^{30}$.

28. SOlEDAD. Memorial historial, pp. 34, 96, 327 y 450. Para la convergencia con otras piezas del momento que imputaban "la esclavitud de la nación" a la actuación de los "condes don julianes" del Consejo de Estado, véase, Razón contra la proposición de los más flacos ministros del Consejo de Estado, BN. Mss. 2569, ff. 264-274.

29. Soledad. Memorial historial, pp. 80, 94 y 345. Como ilustración de la presencia de las comunidades de Castilla en la retórica política catalana del momento se puede consultar el Discurs de Don Emmanuel Ferrer i Sitges, (1713), que cito por la edición de Joaquim ALBAREDA de los Escrits politics del segle XVIII. I (Vic: Eumo/IUHJVV, 1996), p. 108. Y para el bloqueo del tímido repunte de la memoria constitucional del reino de Castilla promovido en los momentos finales del Seiscientos por las voces que identificaban a las Cortes como la instancia llamada a solventar el dilema sucesorio, véase García-BADEll, Luis M. ${ }^{a}$. "La sucesión de Carlos II y las Cortes de Castilla". Cuadernos de Historia del Derecho, 13, 2006, pp. 111-154.

30. Soledad. Memorial historial, pp. 70, 120 y 342 . 
Siendo no obstante sabido y bien sabido que "usan los togados de falsas e indecentes presunciones, que publican para que no llegue el caso de valerse el Rey de sus reinos y Ciudades", el primer paso hacia la sanación pasaba irremediablemente por el asalto a su fortaleza ${ }^{31}$. La "rigurosísima reformación" del Consejo y Cámara de Castilla, llamada a fosilizar la «soberanía en que pone a estos togados dicha Cámara", y consagrada a invertir de forma radical la política disposición de cosas por la que estos maquiavelistas venían "haciendo Parlamento al Consejo de Castilla", emergía así como la verdadera llave maestra que podía posibilitar al "nuevo Salomón" emprender las curas conducentes a la resurrección de España e incluso a su propio renacimiento como Monarchia al que le abocaba su conversión bajo el despotismo en un "monstruo de mil cabezas" ${ }^{32}$. Pese a la aparente sintonía con la referencias al "defecto de soberanía" o a la divisa del "rey esclavo" que pronto formalizaría Melchor de Macanaz desde posiciones de implicación dinástica inversas, la "esclavitud" y el "defecto" no se vinculaban por tanto en el $\mathrm{Me}$ morial historial con el presupuesto de una constitución tradicional que despojaba al príncipe de cualquier facultad de disposición sobre los derechos territoriales sino con el despliegue "parlamentario" del Consejo de Castilla ${ }^{33}$. Debiendo hacerse extensiva a los consejos de Hacienda y de la Mesta, el propio sentido en el que esa reformación se proyectaba como rigurosísima no era algo que además quedara sin especificarse, pues su enunciado se encuadraba y arraigaba explícitamente sobre una lógica encaminada a circunscribir la función de los Consejos «a solo lo judicial", y así "a la atención de lo civil y criminal", sin la participación alguna en el "gobierno político y económico". De ahí precisamente que el círculo reformista proyectado por el Memorial se cerrase con el ferviente llamamiento para que ese "libertador" comprendiera la dimensión imperativa que entrañaba la paralela incorporación a su anclaje político de una "nobleza española [cuya] fuerza natural había de aplicarse en los gobiernos, virreinatos embajadas y armadas de mar y tierra ${ }^{34}$.

Ahora bien, el convencimiento de que los togados habían de intentar desbaratar aquel viraje y de que su estrategia defensiva les induciría a esgrimir el peligro que para la integridad de la soberanía encerraba el predicado fortalecimiento de la posición constitucional de las Cortes, obligaba a su vez al Memorial a atender con detalle un flanco previo y decisivo para la suerte del combate: instruir al "nuevo Salomón" sobre los cantos de sirena que dedicados a la soberanía procurarían embaucarlo en la batalla. La clarificación de la identidad del único sujeto político del que había de temerse una posible metamorfosis "parlamentaria" se interiorizaba por eso mismo como un empeño en el que no debían de escatimarse esfuerzos.

31. SOLEDAD. Memorial historial, p. 168

32. SOlEDAD. Memorial historial, pp. 94, 259-268, 312-313 y 433 y ss.

33. Para el planteamiento de Macanaz, véase, IÑURriTEGUI, José María. Gobernar la Ocasión. Preludio político de la Nueva Planta de 1707. Madrid: Centro de Estudios Políticos y Constitucionales, 2008.

34. SOlEdAD. Memorial historial, pp. 175-176, 313, 319-320, 325 y 334-334. 
"Artificiosamente han persuadido a los Monarcas que no son convenientes las Cortes, con el achaque de que las Cortes se levantarán a Parlamento", rezaba una de las páginas justamente finales del Memorial, "mas esto es mera ficción, y lo que se debe evitar es que el Consejo y Cámara de Castilla no se levante a Parlamento „35. La propia envergadura y magnitud de lo que se había de ventilar en aquella querella sobre el papel que, en una correcta dinámica constitucional, estaban llamados a jugar los distintos miembros del cuerpo político, podía sin embargo requerir la incorporación de mayores precisiones. Así al menos lo entendía Benito de la Soledad, que procedía a deslegitimar con rotundidad y a segar de raíz cualquier resquicio por el que su reivindicación del protagonismo que las Cortes estaban llamadas a tener en la arquitectura política hispana pudiera ser leída, bajo el prisma de la soberanía, como una afirmación de la imposibilidad de concebir el poder del rey al margen del poder del reino: "Son las Cortes una disposición del Monarca para el buen govierno de su Monarchía, y que mejor se guarden las Leyes de su Reyno, porque el Rey no se puede hallar en todas partes; mas lo que hace el Rey con las Cortes lo pudiera hacer por sí solo, porque es supremo legislador y tiene por Derecho natural y de las Gentes obligación a governar y dar y quitar leyes como conviene, ${ }^{36}$

Ninguna contorsión semántica le era en realidad necesaria para situar la cuestión en esos términos. Si a lo largo de toda su exposición no se había cansado de reiterar que el monarca debía "governar como cabeza con entendimiento y razón", y de repetir que las Cortes eran los únicos "miembros" capacitados para "descubrirle esa razón, y obrar con ella en consecuencia", aún mayor había sido el empeño por dejar sentado que su intención estaba lejos de orientarse hacia un requerimiento para que esa "cabeza" dejara de ser absoluta y por tanto mudase su "imperio" en "monarquía templada" ${ }^{37}$. Bien es cierto que, pese a la rotundidad de semejante pronunciamiento, el Memorial no evidenciaba la áspera textura patrimonial que algo después revestiría a algún texto compuesto desde idéntica posición de implicación dinástica. El Memorial no era evidentemente aquel Derecho natural innato de Diego Vincenzo Vidania en cuyo seno se omitían incluso las propias reservas planteadas por la neoescolástica castellana ante cualquier posible expediente de extensión del poder real ${ }^{38}$. Pero su vocabulario no por ello dejaba de ser irreconciliable con la esencia de la lengua y la cultura constitucional de los territorios de derecho propio, y ante todo con su supuesto básico por el que el

35. SOLEDAD. Memorial historial, pp. 315 y 433.

36. SOlEDAD. Memorial historial, p. 437

37. SOlEDAD. Memorial bistorial, p. 14, 15 169, 215 y 238. Para el distanciamiento que así se traza frente a los planteamientos algo posteriores de otros exiliados castellanos, cfr. AlCOBERRO, Agustí. "Monarquía moderada i libertat de la patria. Notes sobre el pensament politic de l'austracisme castellà a l'exili". Pedralbes, 27, 2007, pp. 173-196.

38. IÑurRitegui, José María. Reescribiendo a Grocio. El Derecho natural innato de Diego Vincenzo Vidania. En prensa. 
rey y el reino no se entendían tanto como poderes, en sentido estricto, sino como elementos de un orden al que se debían. Poniendo de relieve toda la ambivalencia política entonces subyacente bajo la complicidad de los discursos en su doble declinación dinástica, las coordenadas conceptuales con las que operaba Benito de la Soledad daban por sentado que el rey católico "posee todos sus dominios sujetos a su obediencia como absoluto Monarcha y Suprema cabeza, sin que sea esta Monarchía templada sino absoluta, y sin que las Cortes ni otro algún poder pueda embaraçar a Su Majestad en sus acertadas disposiciones "39.

En su particular cruzada contra el despotismo el lenguaje del Memorial no solo venía además a situarse en las antípodas de aquel entendimiento colegiado de la iurisdictio, plasmado con absoluta plasticidad en la figura del Rey en Cortes y que configuraba el motivo de estructura constitucional más largamente sedimentado en la cultura política de alguno de los territorios entonces comprometidos con la causa del Archiduque ${ }^{40}$. La propia naturaleza de los remedios prescritos por Benito de la Soledad para atajar los males de la Monarquía incidía también, y de forma directa, sobre la identidad política de los reinos forales, siendo como eran en su opinión los principales y más imperativos para la conservazzione dello stato la animación de un expediente de "unión de armas" entre los diversos territorios y el establecimiento de un "nuevo sistema de rentas", también uniforme para todos ellos, inspirado en la restitución a las alcabalas de la centralidad que los servicios de Millones le habían arrebatado en el ordenamiento hacendístico monárquico ${ }^{41}$. El Memorial no dejaba además de hacer suyas algunas de las credenciales discursivas históricamente más críticas con la inexistencia de un derecho territorial común para toda la Monarquía. Decía mucho al respecto la mención a la "dificultad" que para la aplicación de aquellas "nuevas disposiciones" entrañaba "la existencia en España de Reynos y Provincias que tienen sus exenciones y privilegios". Y aún decía más que a continuación viniera a decretarse que la única fórmula capacitada para superarla pasaba por "poner a todos en igual disposición con las Castillas, que no gozan de los fueros de los otros Reynos y Provincias " ${ }^{42}$. Pero era sin duda la imagen de la "perfecta unión" de los reinos, y su identificación como aspiración suprema a la que el nuevo Salomón había de entregar su quehacer reformador, la que en verdad fijaba el específico modo de abordaje

39. SOlEDAD. Memorial historial, pp. 178 y ss.

40. Fernández Albaladejo, Pablo. "Lex Regia Arogonensium: monarquía compuesta e identidad de reinos en el reinado de Felipe III". En Materia de España. Cultura politica e identidad en la España Moderna. Madrid: Marcial Pons, 2007, pp. 65-91.

41. Soledad. Memorial historial, pp. 214-290. Para contextualizar esa crítica al desajuste constitucional provocado por el devenir del servicio de Millones, ForTEA José Ignacio. "Las Cortes de Castilla y su Diputación en el reinado de Carlos II". En Eiras Roel, Antonio (ed.). Actas de las Cortes del Reino de Galicia. Santiago: Xunta de Galicia, 2003, vol. XII, pp. 63/98 y CÁRCELES DE GEA, Beatriz. Reforma y fraude fiscal en el reinado de Carlos II. La Sala de Millones (1658/1700). Madrid: Banco de España, 1995.

42. SOlEDAD. Memorial historial, p. 295. 
que el Memorial dispensaba a los modos históricos de composición entre el orden "particular" de los reinos y el "universal" de la monarquía.

Ensalzar la "hermosura de la uniformidad", y más concretamente, "la hermosura y admiración que causará ver todos los Reinos y Provincias de España, con todo lo demás que pertenece a esta Monarquía, en una uniformidad y con una igualdad en mantener a su Rey", no impedía desde luego que el Memorial se despojara formalmente de todo el ropaje semántico propio y distintivo de los llamamientos a emprender un proceso de derogación de la vieja planta de la monarquía. La puntualización al respecto no podía ser más directa, afirmándose como se afirmaba que "por ningún acontecimiento insinúo que se embaracen los Privilegios, Fueros o Leyes de los Reynos, Principados o Provincias que tienen sus exenciones, porque estos Reynos asistan a Su Magestad en la forma que de nuevo se tome». Consciente de la delicadeza requerida por la cuestión, de hecho era en la firma determinación para dictar una nueva planta que liquidase los ordenamientos privativos de los reinos donde el Memorial cifraba una de las muescas básicas del gobierno despótico que Luis XIV aspiraba a instaurar en la Monarquía. Nada al respecto interesaba más a Benito de la Soledad que el marcar y remarcar la distancia que mediaba entre el sentido de su propuesta y la intención con la que Luis XIV había de alzar la bandera de la uniformidad territorial en materia fiscal para servirse de las antiguas querellas regnícolas hispanas y así despertar la pasional complicidad de los castellanos en su proyectado barrido de la constelación de derechos privativos de los reinos ${ }^{43}$. Si en ese orden de cosas su referencia a las "nuevas disposiciones" que habían de guiar en materia de rentas y armas la novación de la forma de la Monarquía podía dar lugar a lecturas e interpretaciones confusas, y cuestionar su grado de respeto hacia los Sagrados misterios de la justicia hispana que aquel mismo año de 1703 desvelaba en Hannover Gerardo Ernesto de Frankeneau, tampoco se omitían precisiones. Y entre ellas, encabezándolas, las referidas al talante no derogatorio sino regeneracionista con el que tan fervientemente propugnaba su adopción.

Lejos así de presentarse como alternativas a las "antiguas leyes de los reinos", en las que reconocía estar "prevenidos todos los aciertos que precisan a una Monarchía para su manutención y aumento", aquellas anheladas nuevas disposiciones se figuraban como la savia necesaria para que las mismas, "que al presente se hallan todas viciadas y corrompidas en la Monarquia Española", pudieran mantener$s e^{44}$. Ahora bien, con todo y con eso, el único camino que en su obra se atisbaba para el porvenir no dejaba de ser el de una Monarquía en la que, "desvanecida toda desigualdad, participa cada parte del cuerpo lo que le toca", lo cual, evidentemente, distaba mucho de ser un mero retorno a aquellos tiempo pasados que se decían felices. Además, y por mucho que el Memorial desplegase el manto retó-

43. SOlEDAD. Memorial historial, pp. 40-46 y 296-301.

44. SOlEDAD. Memorial historial, p. 190. 
rico de las antiguas leyes de los reinos, en ningún momento se ocultaba que eran las de un solo reino, las leyes de Castilla, las que habían de infundir y encuadrar la gestación y concreción de la igualdad. Y es que, en realidad, y a medida que adquiría espesor, los ecos que parecían resonar con más fuerza en sus páginas no eran los de un difuso pasado sino los más concretos del Gran Memorial y del proyecto de Unión de Armas del Conde-Duque de Olivares, nudos de un tiempo no precisamente feliz ${ }^{45}$.

La insatisfacción que con su retórica de la uniformidad evidenciaba Benito de la Soledad respecto a las que habían sido las tradicionales formas de unión de los reinos ya mostraba sin duda un franco paralelismo con la visión que en su momento había llevado a Olivares a concebir su propuesta ${ }^{46}$. Y ese paralelismo se acentuaba aún más por la plena coincidencia de uno y otro al determinar la razón más sustantiva por la que los reinos habían de convenir con una estrategia que les requería una lectura menos esencialista de su identidad territorial: la existencia de un ámbito prepolítico, y así por supuesto anterior a la conformación de cualesquiera Sagrados misterios, que informado por la ley divina y la ley natural tenía en el amor su esfera de normatividad. Las implicaciones consustanciales al "Vínculo de conciencia" entre el monarca y sus súbditos fraguado en las coordenadas de ese ordo amoris difícilmente podían ser además enunciadas con mayor coherencia que la que proporcionaba haberse antes precisado, al modo en que lo hacía el Memorial que por algo desde su titulación se presentaba también como manual de "política cristiana", "[que] mis proposiciones nacen de principios ciertos de teología y de las leyes del derecho divino, natural y de gentes con razones naturales inferidas científica y escolásticamente de universales y evidentes principios ${ }^{47}$. En realidad ese era el canon de toda la cultura propia cartografiada en el atardecer del Seiscientos por la Bibliotheca Hispana de Nicolás Antonio. Lo que sin embargo, y aún sin dejar de ser canónico, podía ya no serlo tanto, era la visibilidad y hondura de la huella que sobre aquel tronco común de comprensión de la política dejaban impresos los planteamientos de Olivares en uno de los tramos argumentales cruciales del Memorial. En especial porque a la altura de 1700, tal y como limpiamente lo atestiguaba el Teatro monárquico de Pedro de Portocarrero, con el lenguaje de la "política cristiana" también podía alzarse un discurso de la resurrección de España, y alegarse y alentarse la insurrección frente

45. Fernández Albaladejo, Pablo. "El reinado de Felipe IV: Reformación de la monarquía y Guerras de España". En Eiras Roel, Antonio (ed.). Actas de las Juntas del Reino de Galicia. Santiago de Compostela: Xunta de Galicia, 1997, vol. II, pp. 57-73.

46. Fernández Albaladejo, Pablo. "Unión de almas, autonomía de cuerpos: sobre los lenguajes de unión en la Monarquía Católica, 1590-1630". Despalabro, 5, 2011, pp. 11-18 y ArRIETA, Jon. "Formas de unión de reinos: tipología y casuística en perspectiva jurídico-política (siglos XVI-XVIII)”. En FLORISTÁN, Alfredo (ed.). 1512. Conquista e incorporación de Navarra. Historiografía, derecho y otros procesos de integración en la Europa renacentista. Barcelona: Ariel, 2012, pp. 89-126.

47. SOlEDAD. Memorial historial, pp. 152 y 169. 
el proceso de corrupción de la constitución tradicional objetivada por los maestros de la iuris religio, sin por ello tener que mostrar ninguna complicidad con la letra y el espíritu del Gran Memorial y la Unión de Armas.

La controvertida suerte que aquella propuesta había tenido no era pese a todo algo que pudiera obviarse cuando, más de medio siglo después, el franciscano Benito de la Soledad concebía y componía los memoriales que luego se convertirían en Memorial. La propia solemnidad con la que en la redacción del mismo se procuraba blindar su planteamiento frente a la crítica que pudiera imputarle la voluntad de promover una intervención sobre la constelación de los derechos territoriales demostraba ya tenerla bien presente. Y la misma tampoco parecía ajena a la necesidad sentida por Benito de la Soledad de ir más lejos de lo que podía suponer la mera reedición de aquel discurso y proceder así a la enriquecedora incorporación de variaciones nada insignificantes encaminadas todas a limar sus perfiles más abruptos ${ }^{48}$. La adopción de alguna renovada premisa, como la que posibilitaba situar la propuesta de uniformidad fiscal fuera de la senda de las enquistadas querellas regnícolas y así bajo un más aséptico prisma que por el contrario permitiera reconocer que "el día de hoy los Reynos que gozan de sus privilegios están tan cargados y empeñados como las Castillas", marcaba la pauta en ese sentido. Una pauta a la que se ajustaba luego el acento puesto en que la adopción de la iniciativa de una correspondencia estable en materia militar entre los reinos "que gozan de sus privilegios" no resultaría tan conflictiva como en momentos anteriores si se hacía explícito que la misma, "sin llegarles a esos privilegios, antes manteniéndolos con más autoridad y aumento", vendría acompañada y provista de "considerables gracias para ellos". Revestido ya de por sí de un innegable atractivo, la capacidad del par conformado por la gracia y el desempeño para incidir sobre la predisposición de los reinos a implicarse e involucrarse en la "Sanación" de España basada en la uniformidad se redimensionaba además cuando el Memorial introducía una de sus novedades de más subido valor: diagnosticar como remedio imperativo la inmediata conversión de la monarquía en un espacio no política sino comercialmente plano y así afirmar que a los reinos "se les dará parte en el comercio, en la forma que se dispusiere, para que comercien libres, comprando y vendiendo libre en toda la Monarchia", sin exceptuarse en ello a las Indias, convertidas a lo largo del texto en metáfora de la "desdichada España" al entenderse que «el Nuevo Mundo, si no se corrige mucho, no puede durar largo tiempo debajo de esta Corona ${ }^{49}$.

48. Como los que conservaba en la Consulta del Consejo de Castilla del 6 de diciembre de 1694, articulada sobre la imagen del "lastimoso teatro de Castilla", con su propuesta de que "los reinos unidos a la Corona de Castilla contribuyan para su propia defensa con la proporción correspondiente, pues así es razón y lo persuaden todos los preceptos políticos y naturales" (BN. Mss. 10919, ff. 87-90).

49. SOlEDAD. Memorial historial, pp. 200, 281, 296, 308 y 328. 
No había obviamente en ello ningún parentesco intelectual con la proyección de una resurrección imperial hispana en clave comercial que Andrew Fletcher deslizaba en $1698^{50}$. Al perfilar aquel horizonte de expectativa en nombre del comercio, y con el interés en el punto de fuga, lo que más bien estaba haciendo Benito de la Soledad era cerrar el círculo abierto al rehuir la opción de disponer su escritura al modo olivariano, como exhortación al monarca para que buscase la ocasión de "hacerse rey de España", y adoptar en su lugar la de convertir su texto en un llamamiento al rey, a los reinos y la nobleza para que reconocieran que la crisis política precipitada por el despotismo constituía un momento de oportunidad política para "hacer España". Nada tenía al respecto de casual que la clave de bóveda de la obra fuera el reiterado recordatorio de que "toda la Monarchía se gobierna por el primer móvil, que es España", ni que en su estela se insistiera en los riesgos que entrañaba olvidar que "desde el momento que este primer móvil va todo desgobernado por los jueces que lo manejan, así van todos los demás Gobiernos y Provincias de la Monarchía". Dar por sentadas ambas premisas equivalía por el contrario a anclar el conjunto de su razonamiento sobre una posición de partida en cuyo posterior desenvolvimiento las nuevas disposiciones podían dejar de ser figuradas como imposición y pasar a ser vistas como el fruto de la reciprocidad amorosa que había de madurar en los "leales corazones", con absoluta naturalidad, "Si a los Reynos se les dejara tomar forma para servir a sus Magestades" ${ }^{51}$.

Lo que por tanto competía al "nuevo Salomón" en el cuadro del Memorial era activar una dinámica en la que la nobleza se implicara en el gobierno político y económico y los reinos, investidos de la libertad necesaria, tomaran individualmente forma y a su vez con ella conjuntamente se la dieran a la monarquía. Y era justamente ahí donde las Cortes entraban en escena, al reconocerse en las mismas la única instancia capacitada para transformar la "diversidad de genios" y los "distintos temperamentos" de los reinos en un armónico equilibrio. Pero se trataba de unas Cortes, y en ello se encierra otra de las muescas más distintivas del Memorial, que por la misma función niveladora que así estaban llamadas a desempeñar no eran las propias y estamentales de los diferentes reinos, de cuyo futuro nada se decía. Inspirado en la enseñanza de la filosofía natural cuando predicaba que "aunque una fábrica esté hecha de diferentes materiales, si todos se reducen a igualdad y orden, y se coge bien el centro, todos sus movimientos son iguales y conformes", las Cortes que por el contrario imaginaba el Memorial, y cuya convocatoria anual auspiciaba, resultaban ser particulares, cuando las conformaban los representantes tanto de las cabezas de partido como de los reinos de "dentro de la

50. Fletcher, Andrew. "Discorso delle cose di Spagna". The political works of Andrew Fletcher. Londres: James Battemban, 1737, pp. 179-240.

51. SOlEDAD. Memorial historial, pp. 200 y 297-300. 
España", y generales cuando a ellos se sumaban los "procuradores de los Reinos y Provincias de fuera de la España" ${ }^{52}$.

En consonancia con la propia consideración de las Cortes como la instancia en la que había de apoyarse el monarca a la hora de dar forma al orden político de la monarquía, y aún sin entrar en mayores detalles, venía así finalmente a promoverse un sistema de representación que abarcase toda la extensión de la misma y en cuya definición, obviamente, tampoco cabía esperarse el auxilio de los pretéritos tiempos felices. Antes que histórico, el criterio por el que esas Cortes se definían en sus dos modalidades remitía más bien a la visión disociada entre la nación y la monarquía con la que parecía operar el Memorial al acompasar sus alusiones a la nación española con la continua e invariable distinción entre "los Reynos exentos así de España como de las otras Provincias y Reynos de la Monarquía de España". No obstante, y en la medida en que una y otra se entendían primeramente católicas, tampoco era una cuestión en la que Benito de la Soledad sintiera ninguna necesidad de detenerse. Menos aún cuando se daba por sentado que en el desafío mayúsculo para el que nobleza y los reinos eran convocados se ventilaba la forja del equilibrio interior sobre el que había de alzarse tanto el equilibrio y la "paz permanente y segura" de Europa como "la paz universal de la Iglesia en aumento de la religión" "53. Su discurso de la conservazzione dello stato resultaba ser así también un discurso propio sobre el balance of power, en el que el acceso a la tierra prometida del equilibrio europeo no se localizaba en la repartición sino en la integridad de una monarquía reforzada además en su uniformidad, y a su vez un discurso más clásico en el que las bondades de esa conservación y ese equilibrio continuaban calibrándose con el fiel de una Iglesia. Que ese discurso fuera uno y no trino hacía precisamente que una politica se adjetivara como cristiana, al fundarse, con asunción de la plena autoridad de la teología en su codificación, sobre la comprensión de que "lo político sirve a las leyes civiles, y las leyes civiles y lo político a la ley divina y sacra teología, que en ella están cifradas todas las políticas y leyes naturales ${ }^{54}$.

Un siglo después Agustín de Arguelles no ocultó en las notas de su Examen bistórico el desafecto que profesaba hacia esa musculatura confesional del Memorial historial. Uno de los "primeros rayos de luz" que descubría tras la humillación de la guerra, y que cifraba en la crisis de 1709 con Roma y en el discurso regalista de Melchor de Macanaz, remitía simple y llanamente a lo que en el Memorial se ti-

52. SOLEDAD. Memorial historial, pp. 300, 408 y 433-438.

53. SOlEDAD. Memorial historial, pp. 8-10, 149 y 415 y ss. Como reciente recordatorio del papel decisivo que entonces continuó desempeñando la religión en el desenvolvimiento del orden político europeo, pueden consultarse los trabajos recopilados en OnNEKInK, David (ed.). War and Religion after Westfalia, 1648-1713. Surrey: Ashgate, 2008 y ONNEKINK, David y ROMmELSE, Gijs (eds.). Ideology and Foreign Policy in Early Modern Europe (1650-1750). Surrey: Ashgate, 2011.

54. SOlEDAD. Memorial historial, pp. 152 y 339. 
pificaba como la antítesis de una política cristiana ${ }^{55}$. No por ello se enturbiaba sin embargo su admiración hacia un texto que comprometía al monarca con la convocatoria de Cortes, que determinaba además, y por muy vagamente que fuera, la forma de concurrencia a las mismas de los reinos peninsulares que identificaba como España y del conjunto de los dominios del rey católico a los que reservaba la consideración de monarquía de España, y que fijaba también una agenda de reflexión colectiva sobre la que asegurar la restauración de esa monarquía. Desgajados del suelo teológico sobre el que se alzaban, los remedios que habían de adensar esa agenda, comenzando por la reforma de la administración a partir de una bifurcación de lo judicial y lo gubernativo, le resultaban tan atractivos como para reconocer en su autor un adelantado a su tiempo.

Alcanzar finalmente su exhumación conllevaba en ese sentido un elevado peaje para el propio Memorial. Consumado el fin de su ostracismo en el marco de una tentativa de contextualización histórica de una reforma constitucional, su revalorización pasaba por segregar algunos de los frutos de las raíces mismas de su discurso, por disociar así los remedios propuestos del firme sustrato de política cristiana en el que arraigaba un texto compuesto, ya bajo forma de memoriales, con la intención siempre declarada de "descubrir a Vuestra Magestad un govierno político y christiano que obliga por ley natural y divina a los vasallos de Vuestra Magestad a admitirlo, y a Vuestra Magestad a ejecutarlo, desvaneciendo las presentes disposiciones que, por haver perturbado con ellas las ajustadas leyes antiguas destos reiynos, es contra Dios y derecho natural el mantenerlas ${ }^{56}$. En estrecho paralelismo con lo que luego ha sucedido cuando el relato historiográfico de la guerra de sucesión le ha dado no solo como punto de entrada sino también como exclusivo punto de llegada su adscripción dinástica final, quedaba por tanto así difuminado, cuando no plenamente velado, el valor quizás más sólido que el Memorial puede aportar al conocimiento de la cultura política de su tiempo: el de su capacidad para ilustrar la conciencia que los politicos españoles habían adquirido, ya antes de la formalización de la crisis dinástica, sobre la urgente necesidad de repensar la monarquía y para perfilar a su vez la particular manera en que ese reto introspectivo encaminado a la novación de su tradicional forma de gobierno y ordenación política se pudo fraguar con el utillaje semántico clásico y distintivo de la política cristiana y así desde la más estricta fidelidad a su núcleo identitario confesional.

En la misma medida en que obliga a relativizar la propia trascendencia que al menos en la gestación de esa inquietud introspectiva cabe atribuirse a la crisis dinástica, la propia historia del texto induce en realidad a evitar que el ensimismamiento con la imagen de un autor adelantado a su tiempo, o con la de un autor comprometido con una causa y unos intereses dinásticos, impida reconocer a

55. ARguelLES, Examen histórico, pp. 66-69.

56. BN. V.E/17/9, pp. 4-5. 
quien ante todo era un autor de su tiempo y que ese era un tiempo no necesariamente surcado por lealtades dinásticas prefiguradas y predeterminadas. Que un lustro después de la publicación del Memorial la crítica de los togados y la deslegitimación de la potestad económica del Consejo de Castilla comparecieran con renovada fuerza en una Explicación jurídica que en su momento circuló de forma manuscrita como obra de Luis de Salazar de Castro, y que luego, al editarse en el Semanario Erudito, se atribuyó a Melchor de Macanaz, insinúa alguna pista sobre la distorsión que entraña la desnuda adopción de una clave dinástica en la consideración de los variados y muy diversos argumentos con los que esa atribulada operación introspectiva podía venir sustanciándose desde finales del Seiscientos y procuró encauzarse una vez inaugurada la crisis dinástica ${ }^{57}$. Y en ese mismo sentido apuntaría también el que una de las voces que en la apertura del reinado sugirieron a Felipe V la pertinencia de la convocatoria de las Cortes de Castilla fuera justamente la de aquel Marqués de Villena que unos años antes había mostrado su complicidad con el predicado más constitucional de los memoriales de Benito de la Soledad cuando este lo había visitado en Barcelona para dárselos a conocer $^{58}$.

Franqueada ya la cota de 1700 , el desencanto que al cerrar la escritura del Memorial provocaba en Benito de la Soledad la confianza que el Marqués de Villena depositaba en Felipe $\mathrm{V}$ para asumir una lógica constitucional de ese signo debió obviamente de hacerse extensivo a todos aquellos que, al modo de Pau Ignasi Dalmases, podían al respecto incluso ser más optimistas que el propio Marqués de Villena. Al margen de filiaciones dinásticas, y por su arraigada visión de la crisis dinástica como una ocasión, como un momento de oportunidad política que abría nuevas expectativas para el abordaje de la reformación de España, en 1701 Benito de la Soledad probablemente estaba más próximo al imperativo "depón España el fúnebre aparato" formulado por Gabriel Álvarez de Toledo en un romance heroico que a las "lágrimas obsequiosas que a la inmortal memoria del gran Carlos Segundo" dedicaba ese mismo año la Academia de los Desconfiados

57. Los textos son el, Papel sobre una Consulta del Consejo de Castilla, que trata de la institución de él, su origen y autoridad de Luis de Salazar, Comendador de Zurita en la Orden de Calatrava, Procurador General de esta Orden, del Consejo de las Órdenes y Cronista mayor de Castilla (BN. Mss. 3847) y la Explicación jurídica e bistórica de la consulta que hizo el Real Consejo de Castilla al Rey nuestro Señor, sobre lo que S.M. se sirvió preguntarle, y se expresa en esa obra; con los motivos que dieron causa para la real pregunta y la respuesta. Y defensa legal de una de las principales partes, que componen el todo de la soberanía de su Magestad, en Semanario Erudito. Madrid: Blas Román, 1788, IV, pp. 3/142. Sobre la autoría véase GARCíA-BADELL, Luis M. ${ }^{a}$. "Felipe V, la nobleza española y el Consejo de Castilla: la Explicación jurídica e histórica que hizo el Real Consejo de Castilla atribuida a Macanaz". Cuadernos de Historia del Derecho, 12, 2005, pp. 125-149.

58. Véase VICENT, Ignacio. "Felipe V y la Monarquía Católica durante la Guerra de Sucesión: una cuestión de estilo". Espacio, Tiempo y Forma, IV/7, 1994, p. 414 y SOLEDAD. Memorial historial, pp. 100104 y $156-157$. 
en la que se encuadraba Dalmases ${ }^{59}$. Las tornas, no obstante, oscilaban un año después cuando en los paratextos de una pieza crucial de su querella crítica con el Marqués de Mondejar, la motivada por la determinación de la patria de Paulo Orosio, Dalmases encumbraba la reciente celebración de las Cortes del Principado como el fin de de una larga y penosa travesía para el cuerpo político catalán ${ }^{60}$. De inmediato, cuando la sucesión se hizo guerra, uno y otro, tanto Pau Ignasi Dalmases como Benito de la Soledad, vendrían a militar en el mismo bando y a encuadrarse bajo las mismas divisas dinásticas. Pero en 1703 podía darse el caso de que fuera quien esgrimía un discurso armado en clave de uniformidad, y no quien terminaría vislumbrando la conversión de Cataluña en república como la única posibilidad de preservar su continuidad en la historia, el que pronosticara y advirtiera que había de entenderse que el saldo de aquellas Cortes representaba para Felipe $\mathrm{V}$ una afrenta que este no estaría dispuesto a olvidar ${ }^{61}$.

\section{BIBLIOGRAFÍA}

Albareda, Joaquim. "Por la Patria y sus Libertades. El discurso del asutracismo catalán del final de la Guerra de Sucesión (1713-1714)». En De Benedictis, Angela (ed.). Teatri di guerra: rappresentazione e discorsi tra età moderna ed età contemporanea. Bolonia University Press, 2010, pp. 239-264.

Alcoberro, Agustí. Monarquía moderada i libertat de la patria. Notes sobre el pensament politic de l'austracisme castellà a l'exili. Pedralbes, 27, 2007, pp. 173-196.

Álvarez DE TOLEDO, Gabriel. Exhortase a España a que dexe el llanto de la muerte del rey D. Carlos Segundo y celébrese la venida de su sucesor el rey D. Felipe Quinto. Madrid: Francisco de Villadiego, 1701.

59. Álvarez de Toledo, Gabriel. Exhortase a España a que dexe el llanto de la muerte del rey D. Carlos Segundo y celébrese la venida de su sucesor el rey D. Felipe Quinto. Madrid: Francisco de Villadiego, 1701, p. 3, y Nenias reales y lágrimas obsequiosas que a la inmortal memoria del Gran Carlos Segundo, Rey de las Españas y Emperador de la América, en crédito de su más imponderable dolor y desempeño de su mayor fineza dedica y consagra la Academia de los Desconfiados de Barcelona. Barcelona: Rafael Figueró, 1701.

60. "Pues si todos los Catalanes tanto debieron a sus Augustos Monarcas, quánto debemos los que oy vivimos a nuestro Gloriosísimo Rey? quántos años avía que carecíamos de la vista de nuestros Príncipes? quántos lustros avía que suspiravamos por unas Cortes? todo nos lo ha dado V. Magestad", Dalmases, Pau Ignasi. Dissertación histórica por la patria de Paulo Orosio. Barcelona: Rafael Figueró, 1702, "Al Rey Nuestro Señor".

61. SOlEDAD, Memorial bistorial, pp. 45-46; La Junta General de Braços de 1713. L'ambaixada Dalmases i altra documentaciò (1713-1714). Barcelona: Parlament de Catalunya-Generalitat de Catalunya, 2008, p. 365 y AlBAREDA, Joaquim. "Por la Patria y sus Libertades. El discurso del asutracismo catalán del final de la Guerra de Sucesión (1713-1714)". En De Benedictis, Angela (ed.). Teatri di guerra: rappresentazione e discorsi tra età moderna ed età contemporanea. Bolonia University Press, 2010, pp. 239-264. 
ARGUELLES, Agustín de. Examen histórico de la reforma constitucional que hicieron las Cortes generales y extraordinarias desde que se instalaron en la Real isla de León el día 24 de setiembre de 1810 hasta que cerraron sus sesiones en 14 del propio mes de 1813. Londres: Carlos Wood, 1835.

ARrieTA, Jon. "Formas de unión de reinos: tipología y casuística en perspectiva jurídicopolítica (siglos XVI-XVIII)". En Floristán, Alfredo (ed.). 1512. Conquista e incorporación de Navarra. Historiografía, derecho y otros procesos de integración en la Europa renacentista. Barcelona: Ariel, 2012, pp. 89-126.

BosBach, Franz. Monarchia universalis. Göttingen: Vandenhoeck \& Ruprecht, 1988.

CAPMANY, Antonio de. Centinela contra franceses. Madrid: Gómez Fuentenebro y Compañía, 1808.

CÁRCELES DE GEA, Beatriz. Reforma y fraude fiscal en el reinado de Carlos II. La Sala de Millones (1658/1700). Madrid: Banco de España, 1995.

CONDE DE TORENO. Historia del levantamiento, guerra y revolución de España. Madrid: Imprenta de Tomás Jordán, 1835-1837.

CORTES CONSTITUYENTES de la nación española. Diario oficial de las sesiones de enero y febrero de 1837. Madrid: Imprenta del Eco del Comercio, 1837.

Dalmases, Pau Ignasi. Dissertación histórica por la patria de Paulo Orosio. Barcelona: Rafael Figueró, 1702.

Del Río PARRA, Elena. Cartografías de la conciencia española en la Edad de Oro. México: Fondo de Cultura Económica, 2008.

Domínguez OrTiz, Antonio. La sociedad española en el siglo XVII. Madrid: CSIC, 1963.

EnRíQuez DE CABRERA, Juan Tomás. Manifiesto del Almirante de Castilla Juan Tomás Enríquez de Cabrera y correspondencia con el emperador Leopoldo I. BN, Micro 20048, ff. 70-104.

FernáNDEZ AlBaladejo, Pablo. "El reinado de Felipe IV: Reformación de la monarquía y Guerras de España". En Eiras Roel, Antonio (ed.). Actas de las Juntas del Reino de Galicia. Santiago de Compostela: Xunta de Galicia, 1997, vol. II, pp. 57-73.

Fernández Albaladejo, Pablo. Lex Regia Arogonensium: monarquía compuesta e identidad de reinos en el reinado de Felipe III. En Materia de España. Cultura política e identidad en la España Moderna. Madrid: Marcial Pons, 2007, pp. 65-91.

Fernández Albaladejo, Pablo. La crisis de la monarquía. Barcelona: Crítica-Marcial Pons, 2009.

Fernández Albaladejo, Pablo. "Unión de almas, autonomía de cuerpos: sobre los lenguajes de unión en la Monarquía Católica, 1590-1630”. Despalabro, 5, 2011, pp. 11-18.

FleTCHER, Andrew. Discorso delle cose di Spagna. En The political works of Andrew Fletcher. Londres: James Battemban, 1737, pp. 179-240.

FORTEA, José Ignacio. "Las Cortes de Castilla y su Diputación en el reinado de Carlos II". En Eiras Roel, Antonio (ed.). Actas de las Cortes del Reino de Galicia. Santiago: Xunta de Galicia, 2003, vol. XII, pp. 63/98.

GARCÍA-BADELL, Luis. "Felipe V, la nobleza española y el Consejo de Castilla: la Explicación jurídica e histórica que hizo el Real Consejo de Castilla atribuida a Macanaz". Cuadernos de Historia del Derecho, 12, 2005, pp. 125-149

GARCíA-BADELL, Luis. "La sucesión de Carlos II y las Cortes de Castilla". Cuadernos de Historia del Derecho, 13, 2006, pp. 111-154.

HILL, Ruth. Sceptres and Sciences in the Spains. Four Humanists and the New Philosophy (ca. 1680-1740). Liverpool: Liverpool University Press, 2000. 
IÑURRITEGUI, José María. "Providencia, gracia y virtud: Discurso católico en tiempos de tribulación”. En De Bernardo AREs, José Manuel (ed.). El hispanismo angloamericano. Córdoba: Universidad de Córdoba-Cajasur, 2001, pp. 979-995.

IÑurritegui, José María. Gobernar lo ocasión. Preludio político de la Nueva Planta de 1707. Madrid: Centro de Estudios Políticos y Constitucionales, 2008.

IÑuRRITEGUI, José María. "Jus in armis. Texto y contexto de la Alegación jurídica de Alejandro de Herrera". En MarTín Marcos, David (ed.). Monarquias encontradas. Estudios sobre Portugal y España en los siglos XVII y XVIII. Madrid: Sílex, 2013, pp. 139-175.

La Junta General de Braços de 1713. L'ambaixada Dalmases $i$ altra documentaciò (17131714). Barcelona: Parlament de Catalunya-Generalitat de Catalunya, 2008.

La salud de la Europa considerada en un estado de crisis. Zaragoza: 1694.

Nenias reales y lágrimas obsequiosas que a la inmortal memoria del Gran Carlos Segundo, Rey de las Españas y Emperador de la América, en crédito de su más imponderable dolor y desempeño de su mayor fineza dedica y consagra la Academia de los Desconfiados de Barcelona. Barcelona: Rafael Figueró, 1701.

ONNEKINK, David (ed.). War and Religion after Westfalia, 1648-1713. Surrey: Ashgate, 2008.

OnNekink, David y Rommelse, Gijs (eds.). Ideology and Foreign Policy in Early Modern Europe (1650-1750). Surrey: Ashgate, 2011.

PORTILlo VAldÉs, José María. Revolución de nación. Orígenes de la cultura constitucional en España, 1780-1812. Madrid: Centro de Estudios Políticos y Constitucionales, 2000.

SAlvador, Miguel Francisco de. Verdad politica, Amsterdam: Henri Desbordes, 1694.

SCHILLINGER, Jean. Les pamphlétaires allemands et la France de Louis XIV. Berna: P. Lang, 1999.

SOLEDAD, Benito de la. Memorial historial y política cristiana que descubre las ideas y máximas del Cristianisimo Luis XIV para librar a la España de los infortunios que experimenta por medio de su legítimo Rey Don Carlos III. Viena: Juan Van Ghelen, 1703.

SOLEDAD, Benito de la. Manifiesto que explica el derecho de la Magestad Cesarea del Señor Emperador a la Monarchia de España y evacuativo de la indebida pretensión del Duque de Anjou, que violentamente la ocupa contra el derecho de las gentes, natural, positivo, canónico y civil. Viena: Juan Van Ghelen, 1703.

VICENT, Ignacio. "Felipe V y la Monarquía Católica durante la Guerra de Sucesión: una cuestión de estilo". Espacio, Tiempo y Forma, IV/7, 1994, pp. 397-424.

VICENT, Ignacio. "Entre prudentes y discretos. La conservación de la Monarquía ante el Tratado de Repartición de 1700". Espacio, Tiempo y Forma, IV/9, 1996, pp. 323-337. 